\title{
Intra-varietal variability of Romanesco variety (Vitis vinifera L.)
}

\author{
Massimo Muganu ${ }^{1 *}$, Marco Paolocci ${ }^{1}$, Simona Primiceri ${ }^{1}$, Riccardo Tartaglia ${ }^{1}$, Ilaria Benucci ${ }^{1}$, Martina Cerreti $^{1}$, \\ Claudio D’Onofrio ${ }^{2}$, Anna Rita Paolacci ${ }^{3}$, and Cristina Bignami ${ }^{4}$ \\ ${ }^{1}$ Department of Agriculture and Forest Sciences (DAFNE), University of Tuscia via S. C. De Lellis snc, 01100 Viterbo, Italy \\ ${ }^{2}$ Department of Agriculture, Food and Environment, University of Pisa, Via del Borghetto 80, 56124, Pisa, Italy \\ ${ }^{3}$ Department of Innovation of Biological, Forestry and Agri-Food Systems, University of Tuscia via S. C. De Lellis snc, 01100 \\ Viterbo, Italy \\ ${ }^{4}$ Department of Life Sciences, University of Modena and Reggio Emilia, Via Amendola 2, Padiglione Besta, 42122 Reggio \\ nell'Emilia, Italy
}

\begin{abstract}
Most historical sources that describe the presence of Romanesco variety in vine-growing areas of Lazio Region (Italy) highlighted the variability of morphological traits within the variety. This partly justifies the presence of different synonyms, true or presumed, reported by many authors for this grape variety. With the aim of analysing this variability, eight accessions related to the variety, collected in Lazio Region and grown in the DAFNE grape germplasm collection, have been characterized over five productive seasons. The ampelographic description was carried out using 50 OIV morphological descriptors and ampelometric analyses were carried out on mature leaves by SuperAmpelo software. The DNA of the different accessions, extracted from young leaves, was analyzed using 14 microsatellite loci. Furthermore, at harvest, the grapes of each accession were sampled to assess main compositive characteristics. Results showed differences among accessions on some ampelographic descriptors of the mature leaf, of the bunch, and on phenological stages. Microsatellite profiles allowed for classification of the accessions into three distinct groups. Qualitative analysis of the berry skin showed differences among accessions in the content of the main classes of phenolic compounds.
\end{abstract}

\section{Introduction}

During XIX century, many authors described the presence of cultivated grapevines named "Romanesco" (which means "of Rome") in different areas of Latium region (Italy). For this reason, the name Romanesco should have a geographical origin and is, probably, derived from the name of the wine that the grape variety contributed to produce in the late Middle Ages [1]. Despite much historical information and ampelographic descriptions available on this variety, the presence of different local names linked to its high grape yield (Pagadebito, Pagadebiti, Scassadebiti, Sfasciabotti, Bottaio, etc...), generated possible synonyms and homonyms, also due to the presence of high levels of intravarietal morphological variation. Acerbi [2] described the variety Bello Romanesco in which the name "Romanesco" is bound to the name "Bello". Furthermore according to Marzotto [3], Bello Romanesco shows morphological traits similar to the most vigorous Bellone variety. Functional characteristics were studied on accession referable to the Romanesco variety [4]. The aim of the present work was to characterize the existing variability within recovered accessions by ampelographic and ampelometric methods, SSRs analysis and, additionally, to assess grape quality at harvest.

\section{Material and methods}

\subsection{Sampling and plant material.}

The study was carried out on 8 accessions described as Romanesco or related synonyms collected from different areas of the Latium region: RO VT2, RO VT4, RO VT5, RO VT 8, RO VT9, PAM VT1, BEL VT1, BEL VT2. Vines are grown at the experimental farm of Tuscia University, grafted on 420A, Guyot-trained and $3 \times 1.5$ m. spaced.

\subsection{Ampelographic and Ampelometric description.}

Ampelographic data were collected during 2013, 2014, 2015, 2016 and 2017 according to the Organisation Internationale de la Vigne et du Vin (OIV) descriptor list [5]. Fifty morphological descriptors relative to vine shoot, young leaf, mature leaf, inflorescence, bunch, berry and seed were used. Data on the main phenological

Corresponding author : muganu@unitus.it 
phases were collected according to OIV. From berry set to veraison, 20 mature leaves per each accession were sampled and analyzed by software "SuperAmpelo" [6]. Biometric measurements of bunch, berry and seed from 10 bunches collected from ten different vine shoots were carried out at harvest.

\subsection{DNA extraction and microsatellite analysis.}

Young leaves from near the shoot tip were collected and rapidly frozen. DNA extraction and SSR analysis were performed as reported in D'Onofrio et al. [7].

Each sample was analyzed at 14 SSR loci: VVS2, VVMD5, VVMD7, VVMD27, ZAG62, ZAG79, VVMD25, VVMD28, VVMD32, VVMD6, VVMD17, VVMD21, VVMD24, VMBC11.

Variety identity was analyzed by comparing the microsatellite profiles with information in the Italian Vitis Database [8], other grapevine databases, and the literature. A cluster analysis was performed by Population 1.2.31 and MEGA-6 software.

\subsection{Qualitative analyses on mature grapes}

One hundred and fifty berries per each accession were sampled three times per season from selected bunches, and divided in two different subsets for the qualitative analyses at harvest. Berries were crushed and the following measures were carried out on must: total soluble solids (TSS) content ( ${ }^{\circ}$ Brix), by optical refractometer OPTECH Mod. RZT ATC, pH, by $\mathrm{pH}-$ meter HANNA Instruments model HI 8417, titratable acidity ( $\mathrm{g} / \mathrm{L}$ of tartaric acid), by dilution of a sample of $10 \mathrm{ml}$ of must with $40 \mathrm{ml}$ of distilled water and subsequent titration with $0.1 \mathrm{~N} \mathrm{NaOH}$ to the neutralization point $(\mathrm{pH}=8.1)$. Further, two hundred berries were sampled and the following qualitative parameters of the skin were assessed: total polyphenols and flavan-3-diols (vanillin assay) according to Di Stefano e Cravero [9], catechins content according to Ivanova et al. [10].

\section{Results and discussion}

\subsection{Ampelographic and Ampelometric characteristics}

Phenological observations showed differences among accessions. BEL VT1 e BEL VT2 showed earlier budburst and berry ripening compared to other genotypes. (Table 1).

Table 1. Values of analyzed phenological OIV descriptors

\begin{tabular}{|c|c|c|c|c|c|c|c|c|}
\hline Characteristics & \begin{tabular}{|l|} 
RO \\
VT2 \\
\end{tabular} & \begin{tabular}{|c|} 
RO \\
VT4 \\
\end{tabular} & $\begin{array}{c}\text { RO } \\
\text { VT5 } \\
\end{array}$ & \begin{tabular}{|c|} 
RO \\
VT8 \\
\end{tabular} & \begin{tabular}{|c|} 
RO \\
VT9 \\
\end{tabular} & \begin{tabular}{|l|} 
PAM \\
VT1 \\
\end{tabular} & \begin{tabular}{|l} 
BEL \\
VT1
\end{tabular} & \begin{tabular}{|l} 
BEL \\
VT2
\end{tabular} \\
\hline Bud burst & 5 & 7 & 5 & 5 & 5 & 5 & 3 & 3 \\
\hline Veraison & 5 & 7 & 7 & 5 & 7 & 7 & 5 & 5 \\
\hline Berry ripening & 7 & 7 & 7 & 7 & 7 & 7 & 5 & 5 \\
\hline
\end{tabular}
differences among accession values relies on vine vigor indices. PAM VT1 and RO VT5 accessions showed the highest values of pruning wood, shoot length and leaf size; RO VT4 accession shown peculiar characteristics, such as the presence of teeth in the petiole sinus that differentiate it from all other accessions (data not shown). The dendrogram presented in Figure 1 shows phenotypic affinity among studied Romanesco accessions based on the analysis of mature leaf.

Considering fruit characteristics, RO VT5, RO VT9 and PAM VT1 accessions showed the highest values of bunch weight (> 400 gr.) (Table 2) and RO VT2, RO VT8 and RO VT9 the highest values of berry weight ( $>$ 3.0 gr.) (Table 3 ).

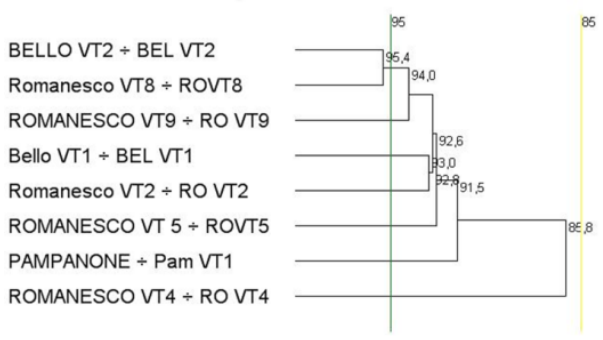

Fig. 1. Phyllometric relationships among Romanesco accessions (from SuperAmpelo)

Table 2. Biometric data: average values of cluster characteristics

\begin{tabular}{|c|c|c|c|c|}
\hline Accession & $\begin{array}{c}\text { Bunch } \\
\text { weight } \\
(\mathrm{gr})\end{array}$ & $\begin{array}{c}\text { Bunch } \\
\text { length } \\
(\mathrm{cm})\end{array}$ & $\begin{array}{c}\text { Bunch } \\
\text { width } \\
(\mathrm{cm})\end{array}$ & $\begin{array}{c}\text { Peduncle } \\
(\mathrm{cm})\end{array}$ \\
\hline RO VT2 & $316.0 \pm 140$ & $15.7 \pm 2.2$ & $11.1 \pm 2.9$ & $2.7 \pm 1.3$ \\
\hline RO VT4 & $297.5 \pm 114$ & $15.3 \pm 2.5$ & $12.9 \pm 2.3$ & $2.5 \pm 0.7$ \\
\hline RO VT5 & $463.4 \pm 159$ & $15.5 \pm 1.5$ & $15.3 \pm 1.5$ & $6.5 \pm 1.3$ \\
\hline RO VT8 & $320.4 \pm 127$ & $16.6 \pm 2.4$ & $12.7 \pm 2.3$ & $2.8 \pm 1.7$ \\
\hline RO VT9 & $401.7 \pm 153$ & $16.6 \pm 2.4$ & $12.7 \pm 2.3$ & $2.8 \pm 1.7$ \\
\hline PAM VT 1 & $440.0 \pm 273$ & $17.7 \pm 2.4$ & $14.2 \pm 3.1$ & $4.0 \pm 0.9$ \\
\hline BEL VT 1 & $243.0 \pm 74$ & $15.6 \pm 0.3$ & $11.4 \pm 1.2$ & $2.3 \pm 0.8$ \\
\hline BEL VT 2 & $313.3 \pm 146$ & $17.4 \pm 1.5$ & $12.5 \pm 1.9$ & $3.3 \pm 0.3$ \\
\hline
\end{tabular}

Table 3. Biometric data: average values of berry characteristics

\begin{tabular}{|c|c|c|c|c|}
\hline Accession & $\begin{array}{c}\text { Berry } \\
\text { weight } \\
\text { (gr) }\end{array}$ & $\begin{array}{c}\text { Berry } \\
\text { length } \\
(\mathrm{mm})\end{array}$ & $\begin{array}{c}\text { Berry } \\
\text { width } \\
(\mathrm{mm})\end{array}$ & $\begin{array}{c}\text { Pedicel } \\
(\mathrm{mm})\end{array}$ \\
\hline RO VT 2 & $3.13 \pm 0.7$ & $16.1 \pm 1.5$ & $15.1 \pm 1.3$ & $6.6 \pm 1.2$ \\
\hline RO VT 4 & $2.4 \pm 0.5$ & $15.0 \pm 1.0$ & $14.9 \pm 1.1$ & $4.9 \pm 0.9$ \\
\hline RO VT 5 & $2.9 \pm 0.7$ & $16.8 \pm 2.1$ & $14.3 \pm 2.6$ & $5.1 \pm 1.9$ \\
\hline RO VT 8 & $3.1 \pm 0.6$ & $15.7 \pm 0.9$ & $15.2 \pm 1.4$ & $6.5 \pm 1.4$ \\
\hline RO VT 9 & $3.2 \pm 0.7$ & $15.7 \pm 0.9$ & $15.2 \pm 1.4$ & $6.5 \pm 1.4$ \\
\hline PAM VT 1 & $2.9 \pm 1.6$ & $14.6 \pm 1.3$ & $14.7 \pm 1.2$ & $6.7 \pm 1.0$ \\
\hline BEL VT 1 & $2.9 \pm 1.5$ & $14.9 \pm 1.4$ & $14.7 \pm 1.0$ & $6.3 \pm 0.5$ \\
\hline BEL VT 2 & $2.7 \pm 1.5$ & $14.5 \pm 2.1$ & $14.7 \pm 1.6$ & $6.4 \pm 0.9$ \\
\hline
\end{tabular}




\subsection{Genetic profile}

A dendrogram, obtained from SSRs data, was constructed using the UPGMA clustering method. Three different cluster of accessions were identified (Figure 2): the first include BEL VT1, BEL VT2, RO VT8 and RO VT2, the second PAM VT1, RO VT5 and RO VT9. RO VT4 DNA profile did not correspond to any of the previous clusters, suggesting different genetic origins. The microsatellite profiles obtained in this study permitted comparison with previously reported profiles, indicating that PAM VT1, RO VT5 and RO VT9 DNA profiles matched the Bellone fingerprints at the CREAVE (Conegliano, Italy).

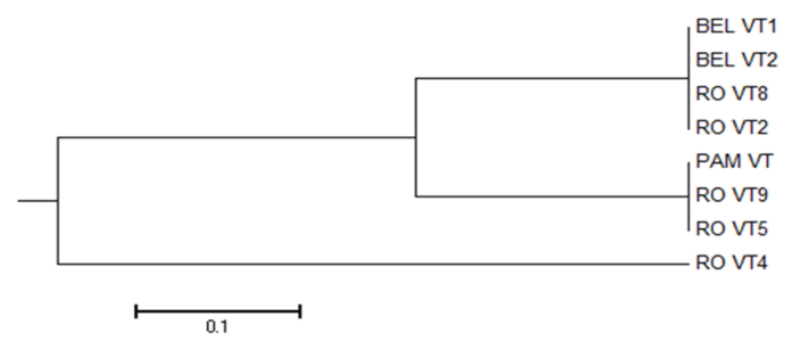

Fig. 2. Genetic relationships among Romanesco accessions

\subsection{Grape qualitative composition}

Berry qualitative data analyzed at harvest distinguished three main groups of accessions according to TSS content (Figure 3). RO VT2, RO VT4, RO VT8 and BEL VT2 showed an average value lower than $20^{\circ}$ Brix compared to BEL VT1, RO VT5, PAM VT1 and RO VT9, which showed values above $20^{\circ}$ Brix and ranging from 20.7 to $21.9^{\circ}$ Brix. RO VT4 showed the lowest value of TSS (15.9 ${ }^{\circ}$ Brix). Additionally, values of $\mathrm{pH}$ and titratable acidity differed among accessions: in particular pH ranged from 3.17 to 3.34 (Figures 4 and 5).

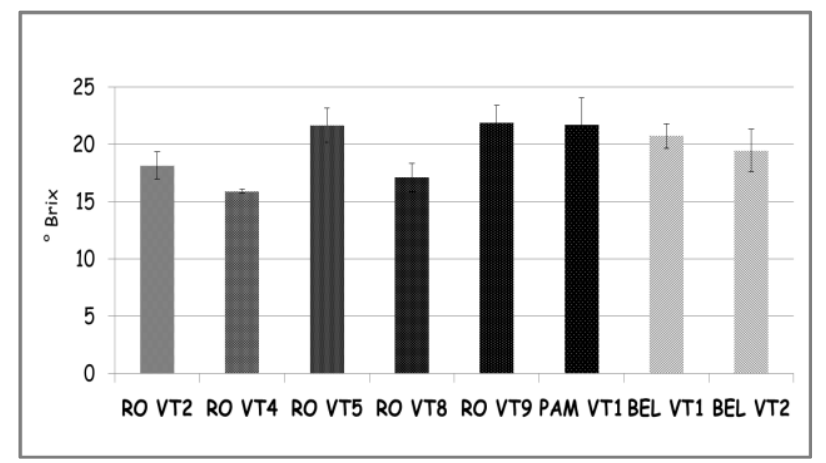

Fig. 3. Average values of ${ }^{\circ}$ Brix at harvest

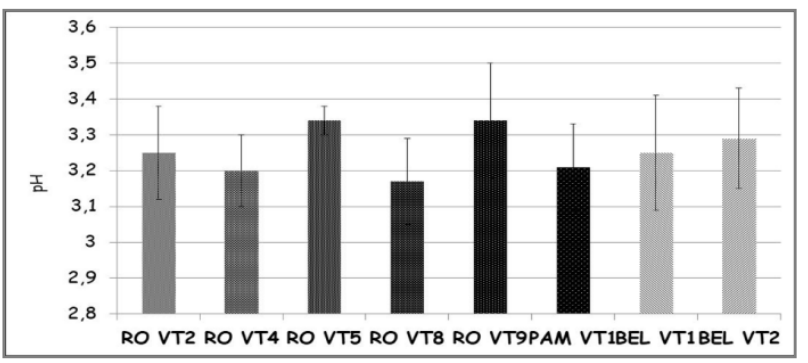

Fig. 4. Average values of $\mathrm{pH}$ at harvest

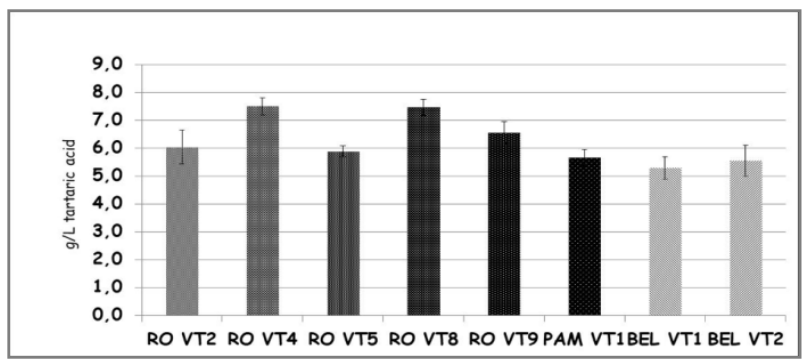

Fig. 5. Average values of titratable acidity at harvest

\subsubsection{Phenolic compounds of the grapes}

The highest content of total polyphenols was detected in RO VT4 accession (Figure 6). The cluster of accessions which includes most vigorous vines RO VT9, RO VT5 and PAM VT1 showed higher content of total polyphenols (ranging from 1081 to $845 \mathrm{mg} / \mathrm{Kg}$ of grape berries) compared to accessions RO VT2, RO VT8, BEL VT1 and BEL VT2, which showed values ranging from 718 to $454 \mathrm{mg} / \mathrm{Kg}$ of grape berries. RO VT4 and PAM VT1 accessions showed the highest content of flavan-3diols (vanillin assay) compared to all other accessions (Figure 7). The cluster which includes accessions with low vigor (RO VT2, RO VT8, BEL VT1 and BEL VT2) showed the lowest content of total catechins compared to RO VT4 and RO VT9 (Figure 8).

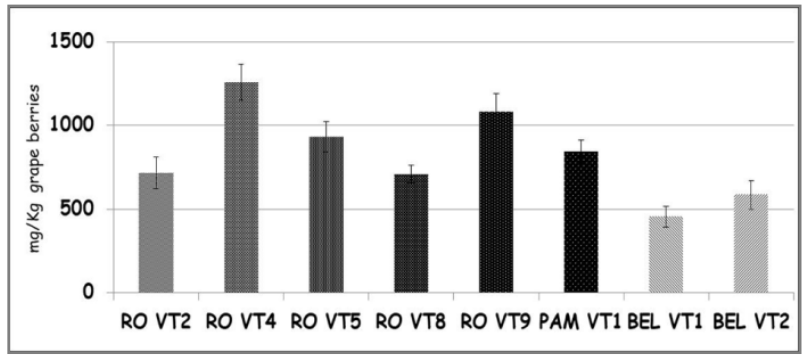

Fig. 6. Average values of total polyphenols at harvest

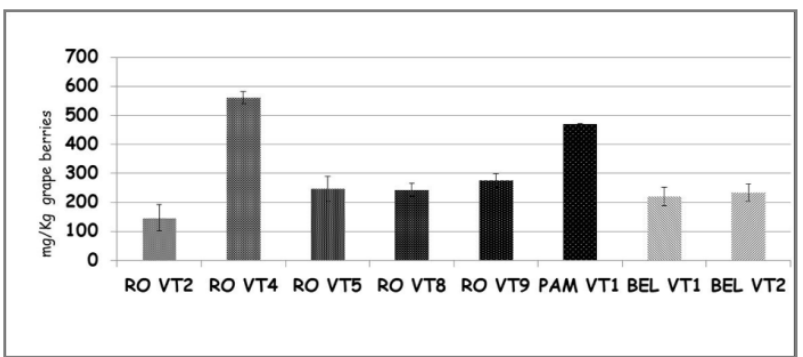

Fig. 7. Average values of flavans (vanillin assay) at harvest 


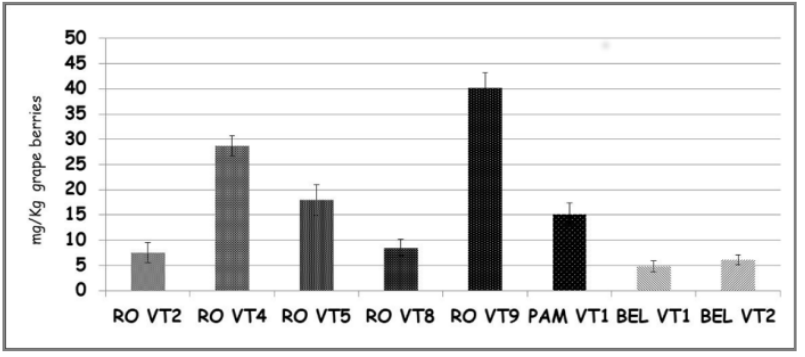

Fig. 8. Average values of total catechins at harvest

\section{Conclusion}

The characterization carried out on accessions referable to the local variety Romanesco confirms that the use of ampelographic and ampelometric methods discriminates differences even between biotypes with very similar morphological traits. The combination of the ampelographic analysis of the grapes with qualitative analyses allows management of future clonal selection according to the oenological needs. The DNA analysis highlighted the possible first-degree relationship between the cluster of accessions that includes RO VT2, RO VT8, BEL VT1, BEL VT2 and the cluster comprising RO VT5, RO VT9 and PAM VT1, whose SSR profile matched with Bellone variety, registered in the Italian National Catalogue.

\section{References}

1. F. Melis, I vini italiani nel medioevo (Mondadori Education, a cura di A. Affortunati Parrini, Firenze, 1984)

2. G. Acerbi, Delle viti italiane (Milano, 1825)

3. N. Marzotto, Uve da vino, 2 Voll. (Tipografia Commerciale Vicenza , 1925)

4. M. Paolocci, M. Muganu, V. Alonso-Villaverde, K. Gindro, Vitis 53, 155-161 (2014)

5. OIV, Organisation Internationale de la Vigne et du Vin: Codes des caractères descriptifs des variétés et espèces de Vitis. http://www.oiv.int/ (2007)

6. C. Soldavini, A. Schneider, M. Stefanini, M. Dallaserra, M. Policarpo, Ital. Hort., 14, 39-40 (2007)

7. C. D’Onofrio, C. Fausto, F. Matarese, A. Materazzi, G. Scalabrelli, F. Fiorani, I. Poli,. Am. J. Enol. Vitic., 67, 120-126 (2016)

8. C. D'Onofrio, G. Scalabrelli, Acta Hort. 1046, 665672 (2014).

9. R. Di Stefano, M. C. Cravero, Riv.Vit. Enol., 44, 3745 (1991)

10.V. Ivanova, M. Stefova, F. Chinnici, J. Serb. Chem. Soc. 75, 45-59 (2010) 